This item was submitted to Loughborough's Research Repository by the author.

Items in Figshare are protected by copyright, with all rights reserved, unless otherwise indicated.

\title{
Biogenic aldehyde determination by reactive paper spray ionization mass spectrometry
}

\section{PLEASE CITE THE PUBLISHED VERSION}

http://dx.doi.org/10.1016/j.aca.2015.01.007

\section{PUBLISHER}

(c) Elsevier

\section{VERSION}

AM (Accepted Manuscript)

\section{PUBLISHER STATEMENT}

This work is made available according to the conditions of the Creative Commons Attribution-NonCommercialNoDerivatives 4.0 International (CC BY-NC-ND 4.0) licence. Full details of this licence are available at: https://creativecommons.org/licenses/by-nc-nd/4.0/

\section{LICENCE}

CC BY-NC-ND 4.0

\section{REPOSITORY RECORD}

Bag, Soumabha, P.I. Hendricks, James C. Reynolds, and R.G. Cooks. 2019. "Biogenic Aldehyde Determination by Reactive Paper Spray lonization Mass Spectrometry". figshare. https://hdl.handle.net/2134/16794. 
Biogenic Aldehyde Determination by Reactive Paper Spray Ionization Mass Spectrometry

\author{
Soumabha Bag ${ }^{1}$, P.I.Hendricks ${ }^{1}$, J.C.Reynolds ${ }^{2}$, and R.G. Cooks ${ }^{1}$ * \\ ${ }^{1}$ Aston Labs, Department of Chemistry, Purdue University, West Lafayette, Indiana 47907 \\ ${ }^{2}$ Centre for Analytical Science, Loughborough University, Loughborough, Leicestershire, UK \\ *Corresponding author: Tel. - +1-765-49-45262; Fax: +1-765-494-9421 \\ E-mail: cooks@purdue.edu
}

Key words: Ambient mass spectrometry; Reactive ionization; Chemical derivatization; Mannich reaction; In-situ analysis; Trace analysis; Amines 


\section{Abstract}

Ionization of aliphatic and aromatic aldehydes is improved by performing simultaneous chemical derivatization using 4-aminophenol to produce charged iminium ions during paper spray ionization. Accelerated reactions occur in the microdroplets generated during the paper spray ionization event for the tested aldehydes (formaldehyde, n-pentanaldehyde, n-nonanaldehyde, n-decanaldehyde, ndodecanaldehyde, benzaldehyde, $m$-anisaldehyde, and $p$-hydroxybenzaldehyde). Tandem mass spectrometric analysis of the iminium ions using collision-induced dissociation demonstrated that straight chain aldehydes give a characteristic fragment at $\mathrm{m} / \mathrm{z} 122$ (shown to correspond to protonated 4-(methyleneamino)phenol), while the arylaldehydeiminium ions fragment to give a characteristic product ion at $m / z$ 120. These features allow straightforward identification of linear and aromatic aldehydes. Quantitative analysis of $n$-nonaldehyde using a benchtop mass spectrometer demonstrated a linear response over 3 orders of magnitude from $2.5 \mathrm{ng}-5 \mu \mathrm{g}$ of aldehyde loaded on the filter paper emitter. The limit of detection was determined to be $2.2 \mathrm{ng}$ for this aldehyde. The method had a precision of $22 \%$, relative standard deviation. The experiment was also implemented using a portable ion trap mass spectrometer. 


\section{Introduction}

Trace organic analysis [1-3] is commonly performed by combining a chromatographic method [4] with mass spectrometry (MS) [5]. Ambient ionization [6-14] is a relatively recent approach to MS analysis which avoids chromatography and is characterized by the absence of any requirement for sample preparation. Paper spray ionization [15-20] is a particularly simple ambient ionization technique which can be employed to study reactions and identify intermediates as well as to measure trace constituents of complex mixtures. Like other spray ionization methods, paper spray is least successful for non-polar or weakly polar compounds. Aldehydes fall into this group and for this reason a reactive version of paper spray is examined here as way to generate an aldehyde derivative during the ionization process. The reaction chosen was that of the aldehyde with a primary amine to generate an iminium ion under the ambient ionization conditions. The generation of a charged product is expected to improve ionization efficiency in a process once known as 'reverse derivatization' [21]. The combined derivatization/ionization process is tested in this study for the analysis of simple aldehydes.

A miniature portable mass spectrometer (Mini 10/12) [22-24] designed to be used in a field setting [25] was also used in this study. The Mini MS/paper spray ionization combination has been successfully demonstrated for the analysis of surface active tetraalkylammonium halides in an oil matrix [26] to simulate oil transmission pipeline monitoring. The closely related ambient ionization method of leaf spray [27] also has been used in-situ with a miniature mass spectrometer to follow the time dependent removal of herbicides from grass leaves [25]. Because of the low pumping speed of the Mini mass spectrometer, the flow of air and ionized sample into the instrument is regulated by a discontinuous atmospheric pressure interface (DAPI) valve [28]. Positioning the paper spray ionization source in front of the DAPI valve allows ions formed by paper spray to be transported into the rectilinear ion trap for tandem mass spectrometric analysis. 
This method is particularly advantageous for the analysis of traces of compounds like aldehydes which have low proton affinities and are present in complex mixtures. Chemical reactions have been shown to proceed at greatly elevated rates in thin drop-cast layers [29] and in electrosprayed microdroplets [30] enabling derivatization to be completed during ionization and keeping total sample analysis times to a few seconds. Both ionization efficiency and molecular selectivity can be improved by chemical derivatization. In addition, the use of an ion trap allows tandem mass spectrometry experiments to be performed in a small and simple instrument. By using what is in effect selected reaction monitoring (SRM) [31] a high degree of confidence is achieved in measuring only the analyte of interest. This approach to the analysis of aldehydes can be contrasted with the more traditional method of gas chromatography mass spectrometry (GC-MS) [32, 33].

One of the driving forces for this study is the fact that the presence of straight chain aldehydes in breath has been linked to the lung cancer [34]. Therefore, easy rapid methods of identification of straight chain aldehydes could be important in diagnosis. In this context, mass spectrometry, especially small, portable, mass spectrometers might be of future interest to allow the measurement in a clinical environment. This is one reason to test the reactive paper spray method of analysing aldehydes with both benchtop and portable mass spectrometers. Breath analysis by mass spectrometry is an area of increasing interest due to its capability for making non-invasive measurements [35-37] which can be used to monitor metabolic state and potentially detecting disease biomarkers [38-40]. It is in this context that we describe a fast, direct and reactive paper spray approach to determine aldehydes using in-situ derivatization with 4-aminophenol to produce iminium ions. 


\section{Experimental}

In-situ derivatization of aldehydes was carried out using 4-aminophenol as the reagent in 80:20 acetonitrile:water. Separate reactions of 4-aminophenol with 1-nonanal and furfural are shown in Scheme 1. The product of this reaction (iminium ion) carries a formal charge on the nitrogen atom which gives it a strong mass spectrometric response. Aldehyde standards and the 4-aminophenol reagent were prepared as solutions in the acetonitrile:water $(80: 20)$ solvent mixture. All the aldehydes as well as the 4-aminophenol were purchased from Aldrich Chemical Company (Milwaukee, WI). In-situ derivatization was performed by first applying $5 \mu \mathrm{L}$ of the 4 -aminophenol reagent $\left(1000 \mu \mathrm{gL}^{-1}\right)$ followed by $5 \mu \mathrm{L}$ of the aldehyde standard (formaldehyde, $\mathrm{n}$-pentanaldehyde, $\mathrm{n}$-nonanaldehyde, $\mathrm{n}$-decanaldehyde, $\mathrm{n}$-dodecanaldehyde, benzaldehyde, $m$-anisaldehyde or $p$ hydroxybenzaldehyde in the range $100 \mathrm{ng} \mathrm{mL}^{-1}$ to $100 \mathrm{\mu g} \mathrm{mL}^{-1}$ ) to the paper spray emitter. Paper spray emitters were isosceles triangles of Whatman no.1 grade filter paper (Maidstone, UK) with typical dimensions of $10 \mathrm{~mm}$ in length and with a width at base of $5 \mathrm{~mm}$. Paper emitters were held in place by a copper clip which was used to apply the high voltage and positioned approximately 10 $\mathrm{mm}$ from the mass spectrometer inlet capillary. The aldehyde/amine mixture on paper was allowed to air dry for 1-5 minutes before solvent addition and spray ionization. Mass spectra from the emitters were recorded by applying $30 \mu \mathrm{L}$ of the paper spray solvent (80:20 acetonitrile:water) and turning on the spray voltage. Simultaneous spraying of the aldehyde and amine from separate paper spray emitters also produced the product. Paper spray signals are transient and quantitative data was obtained by averaging a 0.1 min section of the ion chronogram early in the spray period (total time ca. $1 \mathrm{~min}$ ) when the highest response was obtained. Five repeat experiments were performed at each of the different sample concentrations $\left(0.1,0.5,1,5,10,25,50\right.$, and $\left.100 \mu \mathrm{gL}^{-1}\right)$ enabling determination of the average response and calculation of precision as \% RSD.

Quantitative experiments were carried out using a Thermo LTQ-Orbitrap mass spectrometer (ThermoFisher Scientific, San Jose, CA) operated in the ion trap only mode unless otherwise 
specified. Operating conditions for the mass spectrometer were as follows: paper spray voltage 3.0 kV; capillary voltage $35 \mathrm{~V}$; capillary temperature $275^{\circ} \mathrm{C}$; tube lens voltage $110 \mathrm{~V}$; AGC active. Product ion scans were performed using an isolation window of $2 \mathrm{~m} / \mathrm{z}$ units and a normalized collision energy of $30 \%$ (manufacturer units).

In addition to the commercial Orbitrap mass spectrometer, a portable rectilinear ion trap mass spectrometer (Mini 12) [22-24] was also used in these experiments. This instrument uses a miniature rough pump together with a miniature turbomolecular pump to achieve an ultimate vacuum below 1 $\times 10^{-5}$ Torr. A two-stage Pfeiffer Vacuum diaphragm pump to provide a backing pressure below 2 Torr for the turbo pump, a Pfeiffer TPD 011 (Pfeiffer Vacuum Inc., Nashua, NH, USA, pumping speed $10 \mathrm{~L} \mathrm{~s}^{-1}$ ) constituted the main vacuum components of the system. All components of the Mini 12, including the electronics and vacuum systems, are assembled in an aluminum case, length $58 \mathrm{~cm}$, width $32 \mathrm{~cm}$ and height $40 \mathrm{~cm}$. A discontinuous DAPI valve [28] was used to transfer the ions created by the paper spray ion source into the vacuum system of the Mini 12 for detection. The DAPI valve acts as a mechanical switch, which opens the ion introduction channel for a brief time (10-30 ms) and then closes it for each scan cycle (which includes ion cooling, mass analysis, ion clearance and reset). The pressure inside the vacuum chamber increases considerably (up to $80 \mathrm{mTorr}$ ) when the valve opens to introduce ions (along with air/sample vapor). During this period, the high voltage is turned off. After ion introduction, the channel is closed to allow the pressure to decrease over a time (300-500 ms) until it reaches a value (normally $1 \mathrm{mTorr}$ ) that allows ion manipulation and mass analysis. At this point, the high voltage is turned on and the RF is scanned to perform mass analysis. Each cycle takes around $1 \mathrm{~s}$ and all mass spectra were averaged over at least 2 cycles and are reported without background subtraction. The resolution of the instrument is approximately $0.6-1$ amu/charge (FWHM) in the $\mathrm{m} / \mathrm{z}$ range used. During tandem mass spectrometry, the parameters of the Mini 12 were maintained as follows: isolation waveform (swift) covers $165-177 \mathrm{kHz}$ and is applied 15 times to give isolated ions FWHM 1.5 mass/charge units, AC frequency during mass scan $167.5 \mathrm{kHz}$, AC voltage $6500 \mathrm{~V}, \mathrm{AC}$ time $85 \mathrm{~ms}$. 


\section{Results and Discussion}

Analysis of five straight chain aldehydes of varying size (methanal, 1-pentanal, 1-nonanal, 1-decanal and 1-dodecanal) was first attempted without derivatization. No protonated aldehyde ions were observed during normal paper spray (only background signals were detected during the spray), and these compounds were found to be essentially undetectable by paper spray mass spectrometry without derivatization. Experiments were then performed using in-situ Mannich derivatization with 4-aminophenol to produce the iminium ion and so to indirectly detect the aldehydes.

Four additional aldehydes, namely, benzaldehyde, $m$-anisaldehyde, $p$-hydroxybenzaldehyde and 2furaldehyde were added to the alkyl aldehydes for the next experiments which were performed in two stages. In the first stage, the aldehydes were derivatized and detected as iminium ions. In the second, the iminium ions were analysed using tandem mass spectrometry to produce fragment ions that provided information about the identity of the aldehyde molecules.

Figure 1a shows a reactive paper spray mass spectrum, obtained with the ion trap in full scan mode, for a case in which $100 \mu \mathrm{g} \mathrm{mL}^{-1}$ formaldehyde was mixed with $1000 \mu \mathrm{g} \mathrm{mL}^{-1}$ 4-aminophenol on the paper emitter prior to sample analysis. The base peak in this spectrum is the $[\mathrm{M}+\mathrm{H}]^{+}$of the 4aminophenol at $m / z$ 110. The iminium ion, observed at $m / z 122$ and marked as a black circle [41], is present at approximately $5 \%$ of the base peak intensity demonstrating that this approach can be used to detect aldehydes. Each of the aldehydes including 1-nonanal, 1-dodecanal, benzaldehyde, 1pentanal, 1-decanal, 4-hydroxybenzaldehyde and 3-methoxybenzaldehyde were found to produce iminium ions with 4-aminophenol and these ions appeared at $\mathrm{m} / \mathrm{z} 234$ (Figure 1b), 276 (Figure 1c), 198 (Figure 1d), 178 (Figure S1a), 248 (Figure S1b), 214 (Figure S1c) and 228 (Figure S1d) respectively. Each product ion is indicated in the mass spectrum with a black circle. Plausible structures of the products are shown on the right hand side of each mass spectrum. Some information on the kinetics of these experiments was obtained by shortening the reaction time from 5 min to 1 min but this did not show any effect on the relative intensity of the iminium ion peaks. In 
fact the reaction occurs in the charged microdroplets generated by paper spray ionization [42-46] as demonstrated by mixing formaldehyde and the amine and immediately recording the mass spectrum. The resulting mass spectrum was identical to that shown in Fig. 1a.

Tandem mass spectrometric analysis, performed to structurally characterize the iminium ions, yielded useful information. Fragmentation of the benzaldehydeiminium ion, as shown in Figure 1d, produced a simple mass spectrum with a single intense fragment ion at $m / z 120$ (Figure 2a). Plausibly, this fragment ion corresponds to the loss of neutral benzene (78 $\mathrm{Da})$ from the precursor ion and nominally produces an isonitrile product ion with a triple bond between the terminal carbon atom and the nitrogen atom. Figure $2 \mathrm{~b}$ shows the mass spectrum observed after the product $(\mathrm{m} / \mathrm{z}$ 234 , as in Figure $1 b$ ) was subjected to collision induced dissociation (CID). The main fragment ion in this spectrum, $m / z 122$, corresponds to fragmentation in the alkyl chain (1-nonanal) between the first and second carbon atoms. This fragmentation was observed with all of the straight chain aldehyde-derived iminium ions with the obvious exception of formaldehyde. The presence of this ion is a useful diagnostic to confirm that the species being fragmented contains an aminophenol moiety, and this should be particularly useful when complex mixtures are analyzed. The fragment ion at $\mathrm{m} / \mathrm{z}$ 110 , seen in the full mass spectrum, results from cleavage of the carbon atom bonded to nitrogen and it represents fragmentation back to 4-aminophenol. Taken together, these MS/MS results suggest that the $m / z 120$ fragment ion could be a useful diagnostic to identify aromatic aldehydes, while $m / z 122$ is diagnostic for straight chain iminium ions. Therefore, it is evident that in addition to serving as an aldehyde detection method, tandem mass spectrometry of the derivatives is useful in recognising aliphatic and aromatic aldehydes.

Having established the fragmentation pattern/structural correlation, quantitative analysis was performed by preparing aldehyde standards across a range of concentrations from $100 \mathrm{ng} \mathrm{mL} \mathrm{L}^{-1}$ (equivalent to $500 \mathrm{pg}$ placed on the emitter) to $100 \mu \mathrm{g} \mathrm{mL}^{-1}$ (equivalent to $500 \mathrm{ng}$ on the emitter). A linear calibration plot was obtained between $500 \mathrm{ng} \mathrm{mL}^{-1}$ and $100 \mu \mathrm{gL}^{-1}$ of 1 -nonanal, which is 
shown on Figure 3. This corresponds to $2.5 \mathrm{ng}-500 \mathrm{ng}$ of aldehyde on target. The reproducibility of this method was acceptable for a direct analysis method with an overall \% RSD precision of $22 \%$ for the $m / z 122$ product ion and essentially the same value (21.6\%) for $m / z 110$ (Figure 3). These data show that semi-quantitative measurements can be made on aldehydes with the reactive paper spray ionization method.

\section{Data from Portable Instruments}

The reactive paper spray experiment was tested using the Mini-12 instrument. Two reactions were studied using this instrument. First, the reaction between furfural $\left(100 \mu \mathrm{g} \mathrm{mL}^{-1}\right)$ and 4 -aminophenol $\left(1000 \mu \mathrm{g} \mathrm{mL}^{-1}\right)$ was found to produce an iminium ion in the mass spectrum at $\mathrm{m} / \mathrm{z} 188$ (Figure 4). A plausible product structure is shown in the Scheme 1. The product ion peak was isolated and collision-induced dissociation produced the fragment ion at $\mathrm{m} / \mathrm{z} 120$ characteristic of aryl aldehydes. Responses from lower concentrations of furfural $\left(10 \mu \mathrm{g} \mathrm{mL}^{-1}\right)$ were also recorded. Secondly, 1dodecanal $\left(100 \mu \mathrm{g} \mathrm{mL}^{-1}\right)$ and 4-aminophenol $\left(1000 \mu \mathrm{g} \mathrm{mL}^{-1}\right)$ were reacted to produce an iminium ion $(\mathrm{m} / \mathrm{z}$ 276) which was isolated and fragmented in the Mini 12 (Figure S2). Upon fragmenting this iminium ion, a peak appeared at $m / z 122$, as seen previously in case of benchtop instrument (Figure 2b). This series of measurements and subsequent structural analyses proves that portable mass spectrometers can be utilized besides conventional mass spectrometers in detection and identification of aliphatic and aromatic aldehydes with derivatization methods.

\section{Conclusions}

The data presented here show that reactive paper spray improves the measurement of low proton affinity aldehydes using a Mannich reaction to create iminium ions. Tandem mass spectrometric analysis is shown to produce diagnostic fragment ions that give simple and easily interpreted information on the structure of the iminium ion precursors, enabling alkyl and aromatic aldehydes to be identified. This approach is shown to be semi-quantitative and capable of determining aldehydes 
over the range from $2.5 \mathrm{ng}$ to $500 \mathrm{ng}$ on the paper emitter in a LTQ Orbitrap instrument. The limit of detection was determined to be $2.2 \mathrm{ng}$ of 1-nonanal.

Similar measurements made using the Mini 12 rectilinear ion trap mass spectrometer show that these experiments can be replicated easily and MS/MS information similar to conventional mass spectrometers can also be obtained. Both experiments show that imine formation (through reactive paper spray) can be used to identify aldehydes without GC-MS.

\section{Acknowledgements}

The authors acknowledge funding from the National Science Foundation CHE 1307264. 


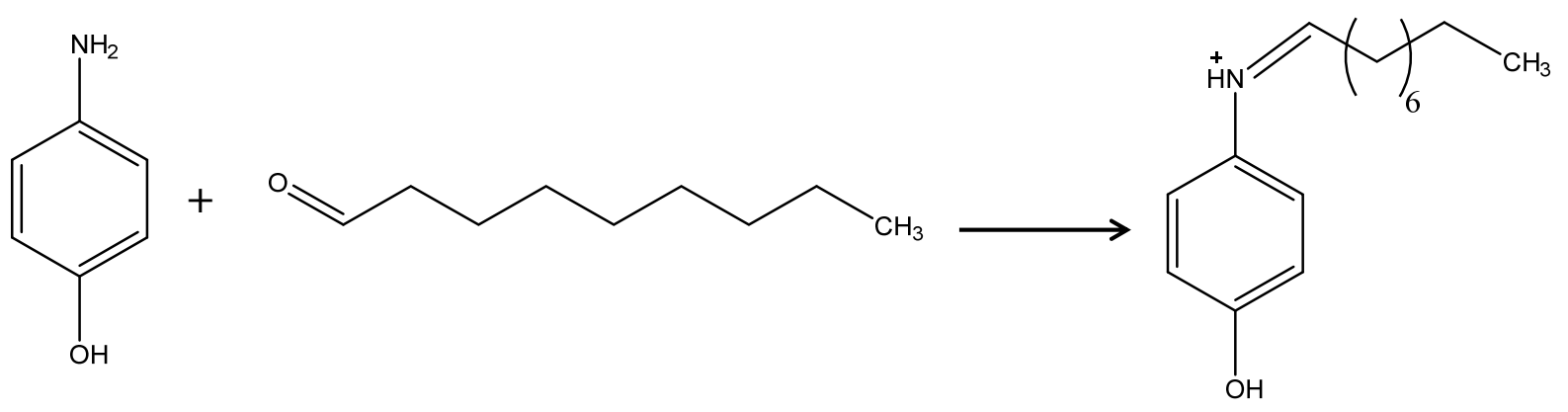<smiles>Nc1ccc(O)cc1</smiles><smiles>Oc1ccc(/N=C\c2ccco2)cc1</smiles>

$\mathrm{Ar}_{-} \mathrm{NH}_{3}{ }^{+}+\mathrm{O}=\mathrm{CH}-\mathrm{R} \longrightarrow \mathrm{Ar}^{-} \mathrm{NH}^{+}=\mathrm{CH}-\mathrm{R} \quad(\mathrm{R}=$ alkyl; Ar, Ar' $=$ aryl $)$ $\mathrm{Ar}-\mathrm{NH}^{+}=\mathrm{CH}-\mathrm{R} \stackrel{\mathrm{CID}}{\longrightarrow} \mathrm{Ar}-\mathrm{NH}^{+}=\mathrm{CH}_{2}+\mathrm{C}_{\mathrm{n}} \mathrm{H}_{2 \mathrm{n}}$

$m / z 122$

$$
\begin{aligned}
& \mathrm{Ar}_{-\mathrm{NH}_{3}}^{+}+\mathrm{O}=\mathrm{CH}-\mathrm{Ar}^{\prime} \longrightarrow \mathrm{Ar}-\mathrm{NH}^{+}=\mathrm{CH}-\mathrm{Ar}^{\prime} \\
& \mathrm{Ar}-\mathrm{NH}^{+}=\mathrm{CH}-\mathrm{Ar}{ }^{\prime} \stackrel{\mathrm{CID}}{\longrightarrow} \mathrm{Ar}-\mathrm{N}^{+} \equiv \mathrm{CH}+\mathrm{Ar}{ }^{\prime} \mathrm{H}
\end{aligned}
$$

$m / z 120$

Scheme 1 


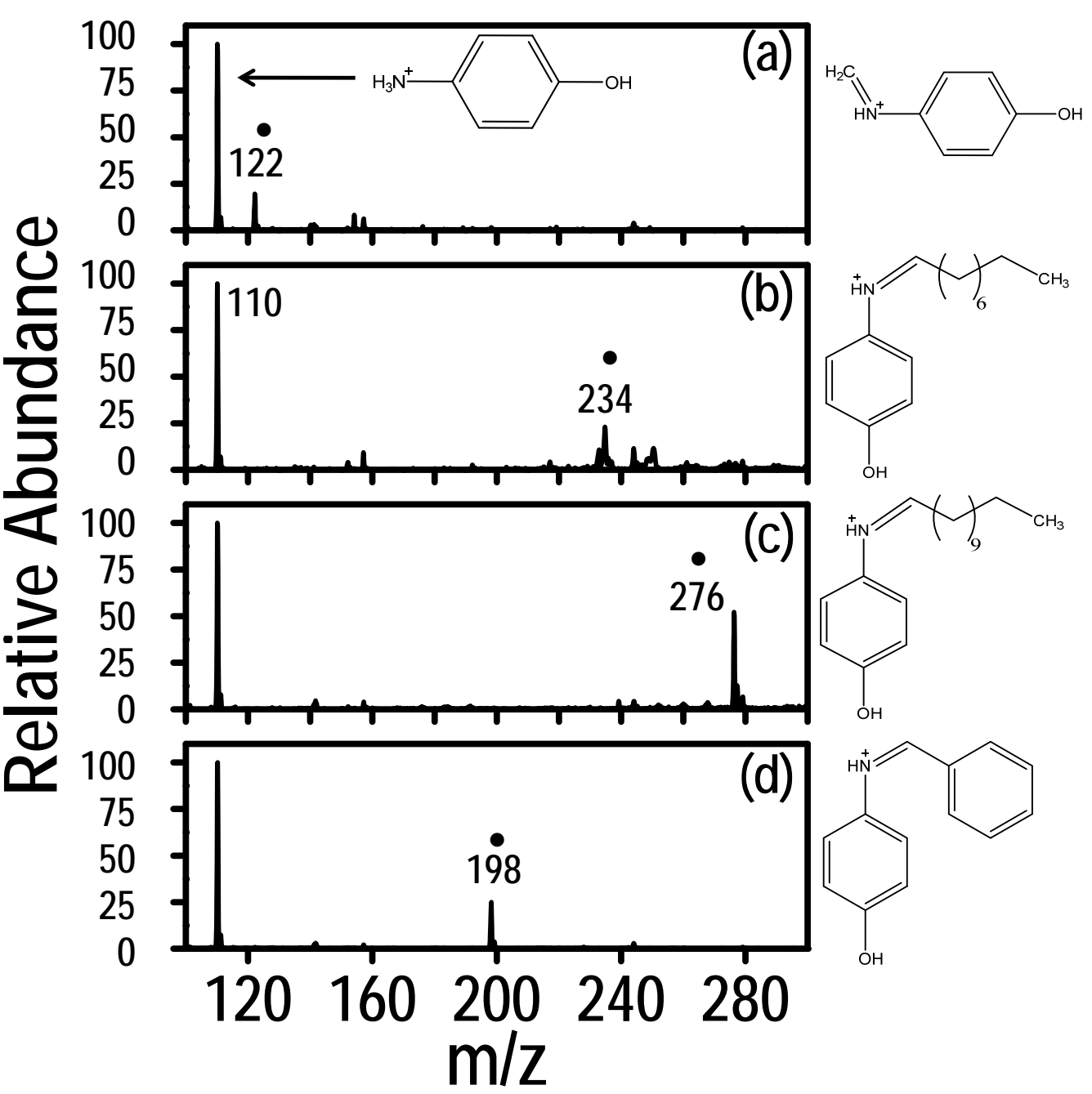

Figure 1 


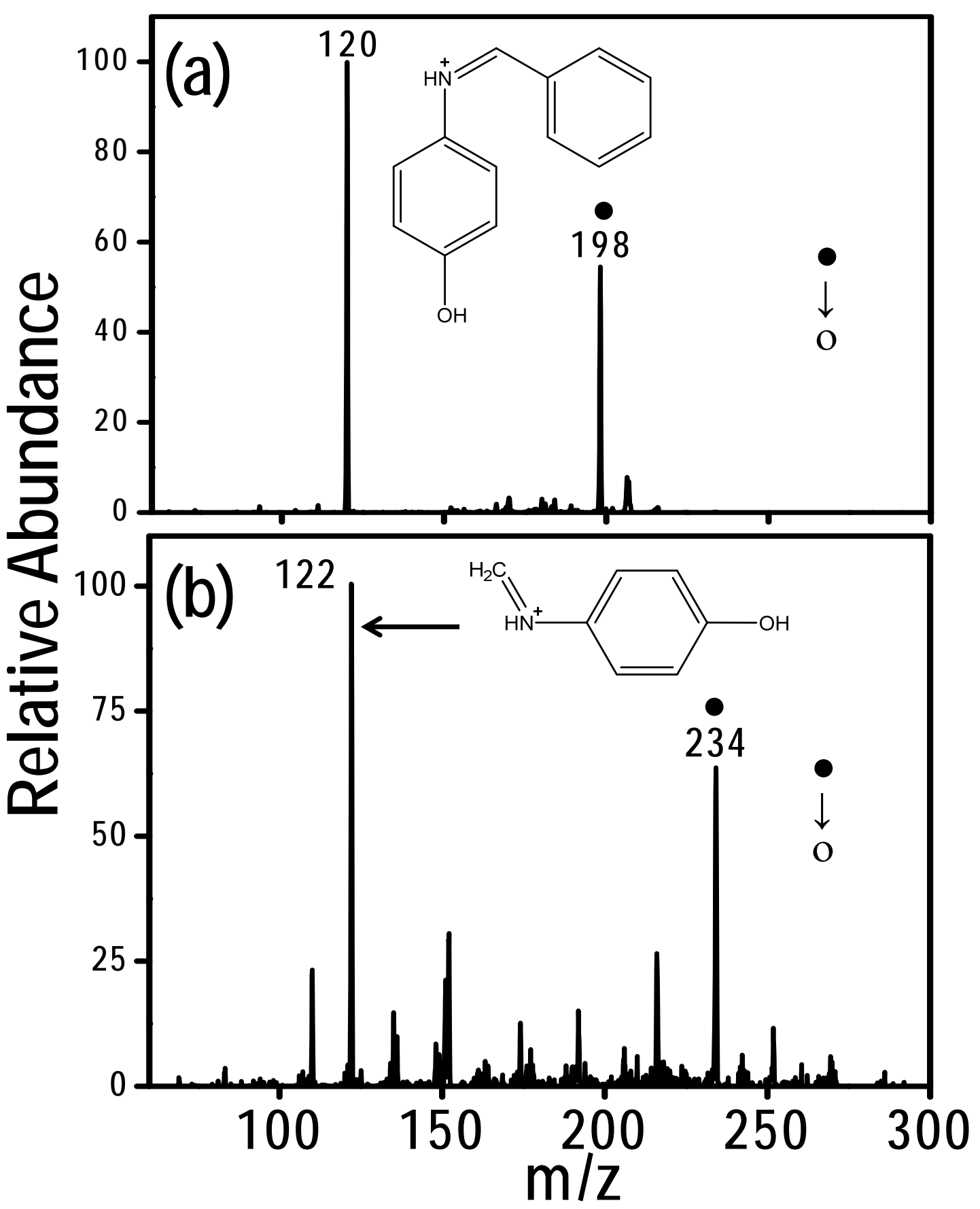

Figure 2 


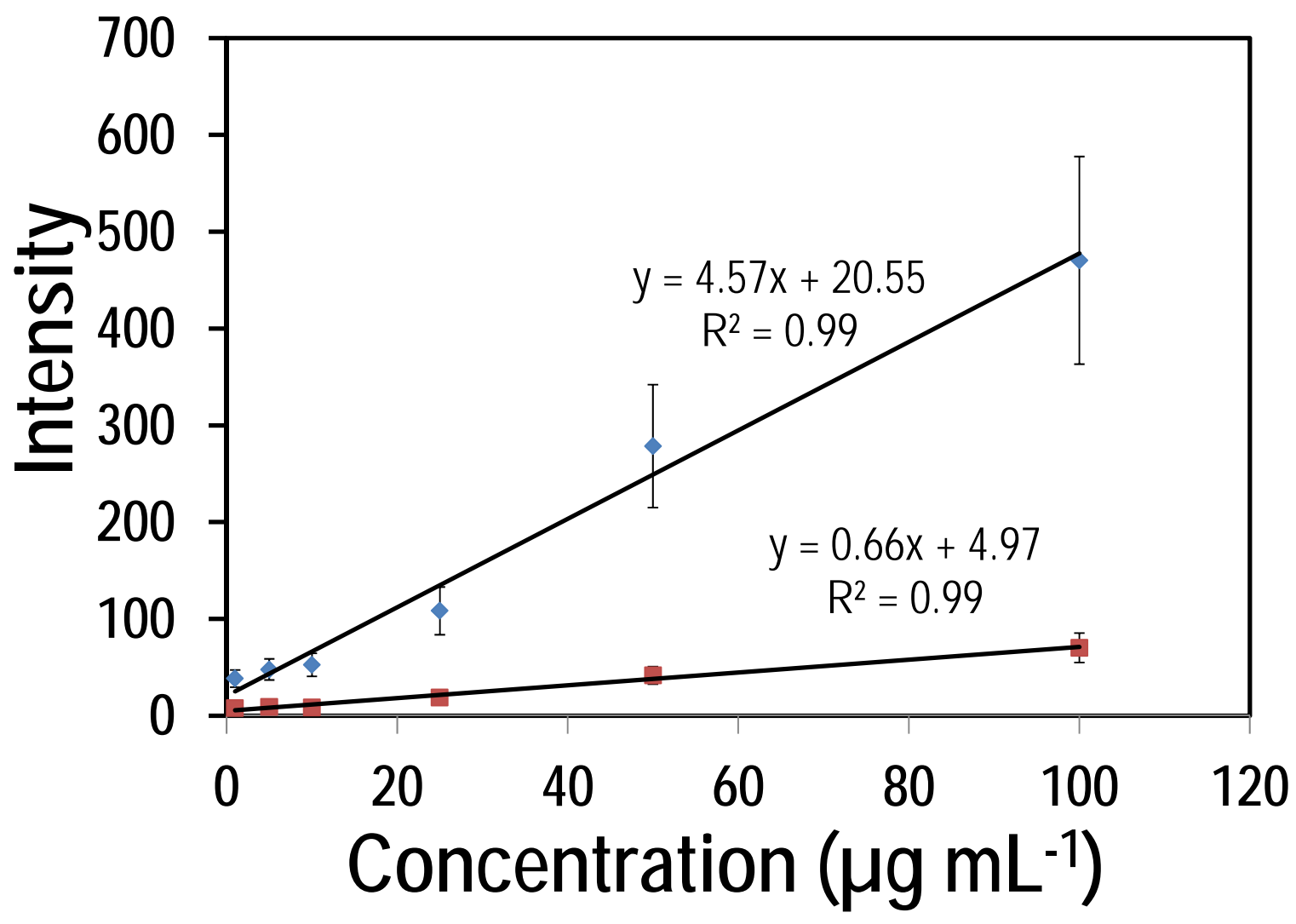

Figure 3 


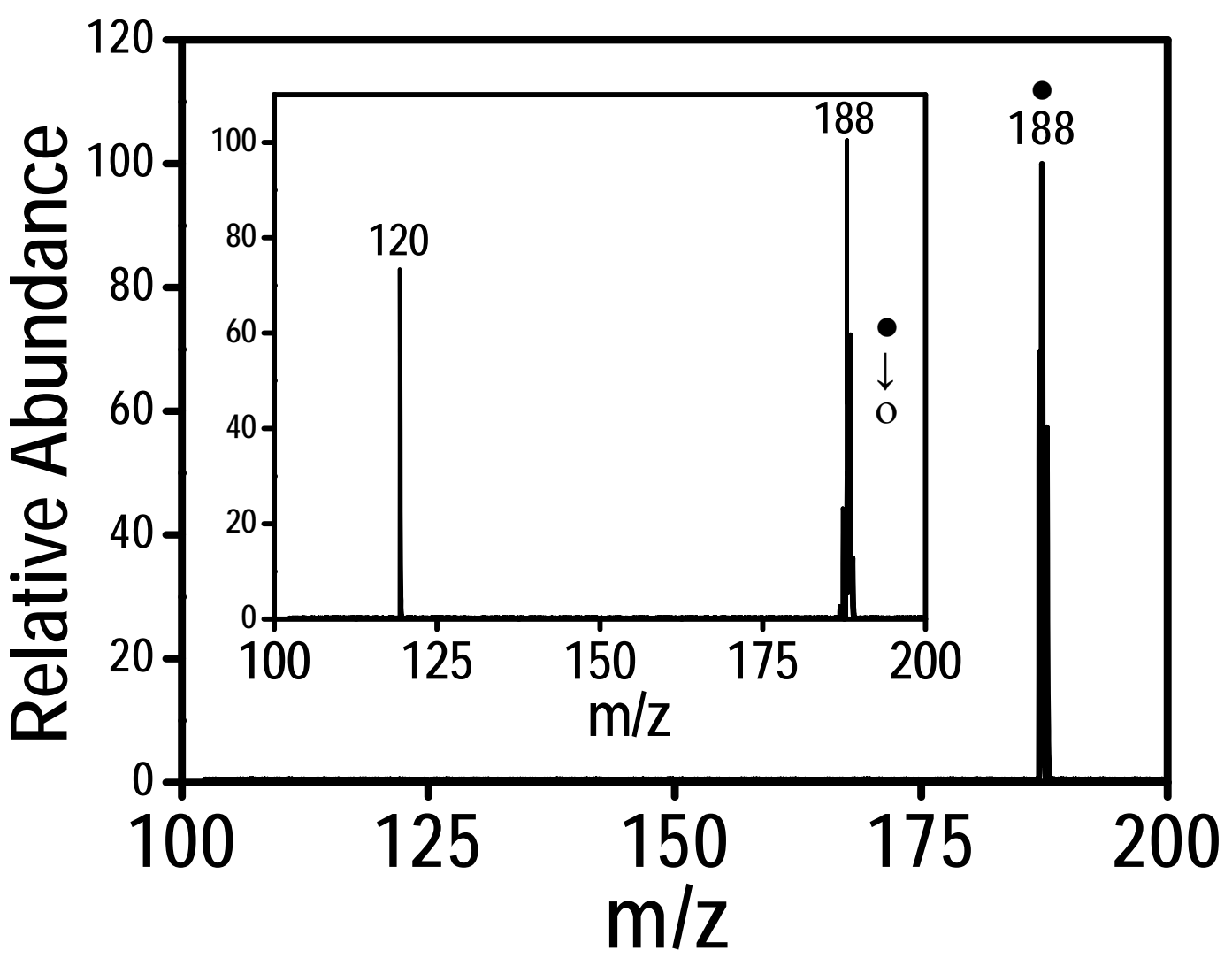

Figure 4 


\section{Figure captions}

Scheme 1: Reaction schemes showing formation of iminium ions using 4-aminophenol in the cases of a typical aliphatic and a typical unsaturated aldehydes (1-nonanal and furfural, respectively). The scheme also shows the CID dissociation of the iminium ions to give the characteristic fragment ions $\mathrm{m} / \mathrm{z} 122$ and $\mathrm{m} / \mathrm{z} 120$ for aliphatic and aromatic aldehydes, respectively.

Figure 1: Reactive paper spray mass spectra of different aldehydes of the same concentration (100 $\mu \mathrm{g} \mathrm{mL^{-1 }}$ ), a) formaldehyde, b) 1-nonanal, c) 1-dodecanal and d) benzaldehyde recorded using a benchtop instrument. Mass to charge ratio of each reaction product is highlighted as a black circle and the product structure is shown next to each mass spectrum. The signal at $m / z 110$ is due to protonated 4-aminophenol.

Figure 2: a) Product ion MS/MS of the iminium ion ( $\mathrm{m} / \mathrm{z}$ 198) produced by reacting $5 \mu \mathrm{L}$ of $100 \mu \mathrm{g}$ $\mathrm{mL}^{-1}$ benzaldehyde with $5 \mu \mathrm{L}$ of $1000 \mu \mathrm{g} \mathrm{mL}^{-1} 4$-aminophenol. Fragment from iminium ion product appeared at $\mathrm{m} / \mathrm{z} 120$. b) MS/MS of the product $(\mathrm{m} / \mathrm{z} 234)$, produced by reacting $5 \mu \mathrm{L}$ of $10 \mu \mathrm{gL}^{-1} 1$ nonanal reacted with $5 \mu \mathrm{L}$ of $1000 \mu \mathrm{g} \mathrm{m}^{-1} 4$-aminophenol. Product ion was isolated and collision induced dissociation produced a characteristic signal at $m / z$ 122. Note that (b) used ten times less aldehyde (a).

Figure 3: Quantitative response (nominal intensity unit) of the 1-nonanal derivative is shown. The diamonds represents the average intensity of product ion, squares are the intensity of protonated 4aminophenol.

Figure 4: Reactive paper spray mass spectrum of $100 \mu \mathrm{g} \mathrm{mL}^{-1}$ furfuraldehyde $+1000 \mu \mathrm{g} \mathrm{m}^{-1} 4$ aminophenol acquired using a miniature rectilinear ion trap mass spectrometer (Mini-12). Inset shows the tandem mass spectrum of the product ion. 


\section{References}

[1] K. Allam, S. Abdel-Baky, R.W. Giese, Derivatization in trace organic analysis: selection of an inert solvent, Anal. Chem., 64 (1992) 238-239.

[2] L. Brenner, B. Silver, I. Suffet, Experience with commercial systems for computer assisted interpretation of mass spectral data. Application to trace organic analysis of natural waters, J. Environ. Sci. Health, Part A, A13 (1978) 149-166.

[3] R.W. Giese, M. Saha, S. Abdel-Baky, K. Allam, Measuring DNA adducts by gas chromatographyelectron capture-mass spectrometry: trace organic analysis, Methods Enzymol., 271 (1996) 504-522. [4] B. Hemmateenejad, M. Akhond, Z. Mohammadpour, N. Mobaraki, Quantitative monitoring of the progress of organic reactions using multivariate image analysis-thin layer chromatography (MIA-TLC) method, Anal. Methods, 4 (2012) 933-939.

[5] Z.-M. Zhang, J.-F. Liu, R. Liu, J.-F. Sun, G.-H. Wei, Thin layer chromatography coupled with surfaceenhanced Raman scattering as a facile method for on-site quantitative monitoring of chemical reactions, Anal. Chem., 86 (2014) 7286-7292.

[6] N.E. Manicke, M. Nefliu, C. Wu, J.W. Woods, V. Reiser, R.C. Hendrickson, R.G. Cooks, Imaging of lipids in atheroma by desorption electrospray ionization mass spectrometry, Anal. Chem., 81 (2009) 8702-8707.

[7] P. Nemes, A.A. Barton, Y. Li, A. Vertes, Ambient molecular imaging and depth profiling of live tissue by infrared laser ablation electrospray ionization mass spectrometry, Anal. Chem., 80 (2008) 4575-4582.

[8] X. Ren, J. Liu, C. Zhang, H. Luo, Direct analysis of samples under ambient condition by highvoltage-assisted laser desorption ionization mass spectrometry in both positive and negative ion mode, Rapid Commun. Mass Spectrom., 27 (2013) 613-620.

[9] A.K. Badu-Tawiah, L.S. Eberlin, Z. Ouyang, R.G. Cooks, Chemical aspects of the extractive methods of ambient ionization mass spectrometry, Annu. Rev. Phys. Chem., 64 (2013) 481-505.

[10] R.B. Cody, J.A. Laramee, H.D. Durst, Versatile new ion source for the analysis of materials in open air under ambient conditions, Anal. Chem., 77 (2005) 2297-2302.

[11] R.G. Cooks, N.E. Manicke, A.L. Dill, D.R. Ifa, L.S. Eberlin, A.B. Costa, H. Wang, G. Huang, Z. Ouyang, New ionization methods and miniature mass spectrometers for biomedicine: DESI imaging for cancer diagnostics and paper spray ionization for therapeutic drug monitoring, Faraday Discuss., 149 (2011) 247-267.

[12] M.-Z. Huang, C.-H. Yuan, S.-C. Cheng, Y.-T. Cho, J. Shiea, Ambient ionization mass spectrometry, Annu. Rev. Anal. Chem., 3 (2010) 43-65.

[13] N. Malaj, Z. Ouyang, G. Sindona, R.G. Cooks, Analysis of pesticide residues by leaf spray mass spectrometry, Anal. Methods, 4 (2012) 1913-1919.

[14] M.E. Monge, G.A. Harris, P. Dwivedi, F.M. Fernandez, Mass Spectrometry: Recent advances in direct open air surface sampling/ionization, Chem. Rev., 113 (2013) 2269-2308.

[15] Y. Zhang, Y. Ju, C. Huang, V.H. Wysocki, Paper spray ionization of noncovalent protein complexes, Anal. Chem., 86 (2014) 1342-1346.

[16] D.R. Ifa, C. Wu, Z. Ouyang, R.G. Cooks, Desorption electrospray ionization and other ambient ionization methods: current progress and preview, Analyst, 135 (2010) 669-681.

[17] R.D. Espy, A.R. Muliadi, Z. Ouyang, R.G. Cooks, Spray mechanism in paper spray ionization, Int. J. Mass Spectrom., 325-327 (2012) 167-171.

[18] J. Liu, H. Wang, N.E. Manicke, J.-M. Lin, R.G. Cooks, Z. Ouyang, Development, characterization, and application of paper spray ionization, Anal. Chem., 82 (2010) 2463-2471.

[19] H. Wang, J. Liu, R.G. Cooks, Z. Ouyang, Paper spray for direct analysis of complex mixtures using mass spectrometry, Angew. Chem., Int. Ed., 49 (2010) 877-880, S877/871-S877/877.

[20] X. Yan, R. Augusti, X. Li, R.G. Cooks, Chemical reactivity assessment using reactive paper spray ionization mass spectrometry: The Katritzky Reaction, ChemPlusChem, 78 (2013) 1142-1148. 
[21] E. De Pauw, G. Pelzer, J. Marien, J.L. Piette, M.C. Pardon, Hydrophobic reverse derivatization for secondary ion mass spectrometry/fast atom bombardment, Org. Mass Spectrom., 20 (1985) 692693.

[22] Z. Zhang, W. Xu, N.E. Manicke, R.G. Cooks, Z. Ouyang, Silica coated paper substrate for paperspray analysis of therapeutic drugs in dried blood spots, Anal. Chem., 84 (2012) 931-938.

[23] P. Hendricks, J. Duncan, R.J. Noll, Z. Ouyang, R.G. Cooks, Performance of a low voltage ion trap, Int. J. Mass Spectrom., 305 (2011) 69-73.

[24] L. Li, T.-C. Chen, Y. Ren, P.I. Hendricks, R.G. Cooks, Z. Ouyang, Mini 12, miniature mass spectrometer for clinical and other applications-introduction and characterization, Anal. Chem., 86 (2014) 2909-2916.

[25] C.J. Pulliam, R.M. Bain, J.S. Wiley, Z. Ouyang, R.G. Cooks, Mass Spectrometry in the Home and Garden, J. Am. Soc. Mass Spectrom., (submitted article) (2014).

[26] F.P.M. Jjunju, A. Li, A. Badu-Tawiah, P. Wei, L. Li, Z. Ouyang, I.S. Roqan, R.G. Cooks, In situ analysis of corrosion inhibitors using a portable mass spectrometer with paper spray ionization, Analyst, 138 (2013) 3740-3748.

[27] J. Liu, H. Wang, R.G. Cooks, Z. Ouyang, Leaf Spray: direct chemical analysis of plant material and living plants by mass spectrometry, Anal. Chem. , 83 (2011) 7608-7613.

[28] L. Gao, R.G. Cooks, Z. Ouyang, Breaking the pumping speed barrier in mass spectrometry: Discontinuous atmospheric pressure interface, Anal. Chem., 80 (2008) 4026-4032.

[29] A.K. Badu-Tawiah, D.I. Campbell, R.G. Cooks, Accelerated C-N bond formation in dropcast thin films on ambient surfaces, J. Am. Soc. Mass Spectrom., 23 (2012) 1461-1468.

[30] T. Mueller, A. Badu-Tawiah, R.G. Cooks, Accelerated carbon-carbon bond-forming reactions in preparative electrospray, Angew. Chem., Int. Ed., 51 (2012) 11832-11835.

[31] M. de Wit, R.J.A. Fijneman, H.M.W. Verheul, G.A. Meijer, C.R. Jimenez, Proteomics in colorectal cancer translational research: Biomarker discovery for clinical applications, Clin. Biochem., 46 (2013) 466-479.

[32] M.J. Thomas, T.W. Robison, M. Samuel, H.J. Forman, Detecting and identifying volatile aldehydes as dinitrophenylhydrazones using gas chromatography mass spectrometry, Free Radical Biol. Med., 18 (1995) 553-557.

[33] J. Yu, H.E. Jeffries, R.M. Le Lacheur, Identifying airborne carbonyl compounds in isoprene atmospheric photooxidation products by their PFBHA oximes using gas chromatography/ion trap mass spectrometry, Environ. Sci. Technol., 29 (1995) 1923-1932.

[34] P. Fuchs, C. Loeseken, J.K. Schubert, W. Miekisch, Breath gas aldehydes as biomarkers of lung cancer, Int. J. Cancer, 126 (2010) 2663-2670.

[35] M. Basanta, T. Koimtzis, D. Singh, I. Wilson, C.L.P. Thomas, An adaptive breath sampler for use with human subjects with an impaired respiratory function, Analyst, 132 (2007) 153-163.

[36] H. Chen, A. Wortmann, W. Zhang, R. Zenobi, Rapid in vivo fingerprinting of nonvolatile compounds in breath by extractive electrospray ionization quadrupole time-of-flight mass spectrometry, Angew. Chem., Int. Ed., 46 (2007) 580-583.

[37] P. Martinez-Lozano, d.I.M.J. Fernandez, Electrospray ionization of volatiles in breath, Int. J. Mass Spectrom., 265 (2007) 68-72.

[38] W. Cao, Y. Duan, Breath analysis: potential for clinical diagnosis and exposure assessment, Clin. Chem., 52 (2006) 800-811.

[39] F. Gahleitner, C. Guallar-Hoyas, C.S. Beardsmore, H.C. Pandya, C.p. Thomas, Metabolomics pilot study to identify volatile organic compound markers of childhood asthma in exhaled breath, Bioanalysis, 5 (2013) 2239-2247.

[40] B. Grabowska-Polanowska, J. Faber, M. Skowron, P.a. Miarka, A. Pietrzycka, I. Śliwka, A. Amann, Detection of potential chronic kidney disease markers in breath using gas chromatography with mass-spectral detection coupled with thermal desorption method, J. Chrom. A, 1301 (2013) 179-189. [41] J.C. Schwartz, A.P. Wade, C.G. Enke, R.G. Cooks, Systematic delineation of scan modes in multidimensional mass spectrometry, Anal. Chem., 62 (1990) 1809-1818. 
[42] A.K. Badu-Tawiah, D.I. Campbell, R.G. Cooks, Reactions of Microsolvated Organic Compounds at Ambient Surfaces: Droplet Velocity, Charge State, and Solvent Effects, J. Am. Soc. Mass Spectrom., 23 (2012) 1077-1084.

[43] A.K. Badu-Tawiah, A. Li, F.P.M. Jjunju, R.G. Cooks, Peptide Cross-Linking at Ambient Surfaces by Reactions of Nanosprayed Molecular Cations, Angew. Chem., Int. Ed., 51 (2012) 9417-9421, S9417/9411-S9417/9414.

[44] M. Girod, E. Moyano, D.I. Campbell, R.G. Cooks, Accelerated bimolecular reactions in microdroplets studied by desorption electrospray ionization mass spectrometry, Chem. Sci., 2 (2011) 501-510.

[45] X. Yan, E. Sokol, X. Li, G. Li, S. Xu, R.G. Cooks, On-Line reaction monitoring and mechanistic studies by mass spectrometry: Negishi cross-coupling, hydrogenolysis, and reductive amination, Angew. Chem., Int. Ed., 53 (2014) 5931-5935.

[46] R.M. Bain, C.J. Pulliam, R.G. Cooks, Accelerated Hantzsch electrospray synthesis with temporal control of reaction intermediates, Chem. Sci., 6 (2015) 397-401.

\section{TOC}

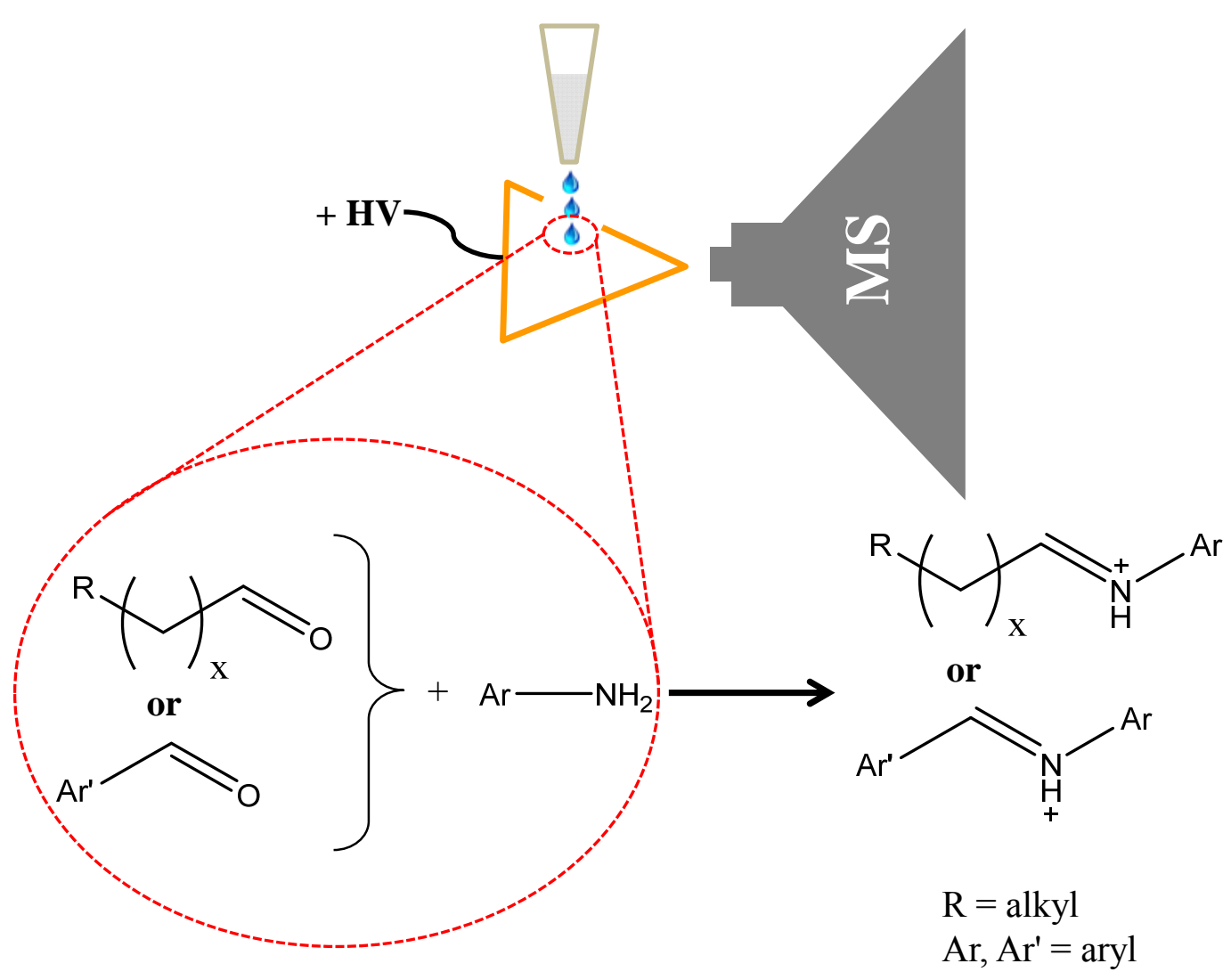

